\title{
Is Proxemics Influencing Leadership?
}

\author{
Alexandru Trifu \\ $\mathrm{PhD}$, Professor, University "Petre Andrei” of Iasi, Romania
}

\begin{abstract}
In this paper, we have no intention to focus on leaders/leadership, on its relationships and debates with management. Our scope is to understand if one major component of the nonverbal communication, i.e. the proxemics, has an influence on leaders/leadership and to highlight the measure of it.
\end{abstract}

Passing through the Fiedler's Contingency Model, as an example, we may say that the charismatic and efficient leader is focused on the on the tandem task-relations. What needs to be kept is the fact we are interested in the existence of a Leader, not of a good leader. It is a contradiction in terms.

In business, but also in politics, the leader is the person who dominates and convinces people around him to work, or to do something for a common goal. Especially politically speaking, in these years it is needed a change of leadership to be accordingly to the new realities and major challenges and defiances of today's world.

Based even on my own experience, studying the activity and behavior of some leaders of our era and papers regarding this main issue, we concluded that the proxemics is influencing leaders/leadership, in a right measure for each leader, but significant for his actions and the state of leadership.

Keywords: proxemics, nonverbal communication, leaders, right distance, efficiency.

JEL Classification: L26, M12.

C The Author, 2017. This article is published with open access at ARMG Publishing.

\section{Introduction}

The society seeks a Leader to define its purpose and to move it forward through selecting and developing people who can successfully invent, do something, sell and provide services to differentiate their business from the competition and solve many of the problems they face (Neculau, 2004: 6).

Every one of us recognizes the importance of the leader when we vote for our political favorites. We realize this matter, so we contribute to the optimal election of a candidate.

The investors recognize the importance of leadership when they say that a good leader can turn a weak plan into a successful plan and that a weak leader can ruin a good plan (Mills, 2005: 2).

The leadership and abilities play a key role in an organization or society. They represent the process through which the employees or people are influenced to achieve their goals as efficiently as possible on the other hand and provide the organization/society with those directions that need to be pursued in order to achieve added value, on the other hand.

A leader plays an important role in assessing the employees' performance, as he is the one who interacts with his subordinates and he is able to be present at their various actions and by observing their behavior directly.

The bigger the changes, the more the leadership style needs to be better organized. The leadership involves a huge responsibility - to make sure you are heading in the right direction, that the decisions you make are knowledge-based. Whatever you do, make sure you act as a leader (Nastase, 2004: 75).

The leader's role has become increasingly complex over time and today it is the "multicolored" center of pressure and expectation. Normally, it must have the science and competence to produce the circumstances where the most capable people can promote their skills and be able to co-ordinate their efforts, remaining committed to the organizational goals (Bennis et al., 2000: 323).

Furthermore, generally speaking about a leader, he is a person with a strong voice who comes out in front and, by his abilities and skills and determines the majority to follow him. In fact, this leader was a more courageous one than those in the majority. This is, maybe, a distinctive feature for a leader: a skillful, de- 
termined, with a different opinion, a person who can get out of the group and to attract the others including the use of all kinds of communication.

\section{The importance of the leadership skills and the role thereof}

The leadership skills are essential for the successful management, and also they are beneficial to a person's career. The managers of Human resource departments believe that a person with leadership skills will bring fame to the company. Among these abilities the listed qualities consist of high qualifications, the ability to make judgments based on knowledge, information and experience, communication skills and interpersonal skills.

Fred Fiedler, a researcher in the field, relates the leadership behavior and the situation that may be favorable or unfavorable in the well-noun Contingency Model which bears his name. ${ }^{1}$

There are three major variables that make the situation favorable or not and that impact upon the role and influence of the leader:

Leader-Member relation- the extent to which the leader provides confidence and is liked by the group members as well as their willingness to follow the leader. If the relations are good, the leader is in a favorable situation to exert his influence.

The Task Structure- the extent to which the task is clearly defined for the group and the extent to which it can be met through detailed instructions and standard procedures. If the task is structured, the influence of the leader will be higher.

The Leader's Position Power- this is the formal authority guaranteed by the organization, through which the leader can influence the rewards and punishments, the promotions or depravations. The more the leader holds greater power, the more this is favorable to him.

The model has to be cautious analyzed by using the best judgment of everyone tries to understand this issue.

\section{Proxemics}

The term was invented, if we may say so, by Edward Hall in the '50-'60 of the previous century and it is dealing with the relationships between an individual and a closer or more distant space (4: chapters IV, $\mathrm{V}$, VIII, X, XII).

Basically, Proxemics relates people to the space this one operates and the the feedback of it (its effect) on our level of comfort or less comfort. The aspect which interests us for the purpose of the present paper is that one regarding the personal territory, not the physical territory, because the first one expresses exactly the level of comfort, trust and de-stress in proximity to others (Sheppard, 1996).

Or, discussing in military terms, proxemics refers to social and personal use of the physical space and interpersonal distance between the leader and the subordinate (Major Crandall, 2007: 224).

Personal territory reflects our comfort level in proximity to others. Depending on the level of intimacy, there are basic ranges for each level.

a. Public space. The distance maintained between an audience and a speaker is generally 12 to 25 feet.

b. Social space. The distance between business associates in communication or strangers in public settings is 4 to 10 feet.

c. Personal space. The distance between close friends or family members, or between strangers waiting in line, is 2 to 4 feet.

The spatial language, a form of nonverbal communication, because we are in the presence of such a message which must be perceived and understood, is related to the personality of the individuals and therefore decisively depends on the participants (the economic actors) on the actions undertaken, on their ego. More or less unconsciously, people need a "territory", a space of maneuver, where they feel safe and feel they can master the situation; in this context, the important person is the one who issues this type of language or who "leads", the way, the entire activity.

\footnotetext{
${ }^{1}$ Fiedler's Contingency Model, www.mindtools.com/pages, accessed August 18, 2017.
} 
The language of space must be thought and framed simultaneously, depending on five significant dimensions: size; degree of intimacy; height; proximity - remoteness; inside - outside. Of course, each one of us has preferences about the distance from those we communicate with and that we try to materialize as appropriate as possible.

It is also Hall who proposes the 4 (four) proxemic dimensions (areas), according to which a human being communicates and reveals his personality, achieving the so necessary contacts in his relationships with the others in the spatial experience he is living. Thus, the following can be distinguished (Leon, 2016: 60-62):

a. The intimate area, range between $0-45 \mathrm{~cm}$;

b. The personal area, range between $46-122 \mathrm{~cm}$;

c. The social area, range between $123-350 \mathrm{~cm}$;

d. The confidentiality zone max. $1 \mathrm{~m}$ and specific to services providers, dealing with the customers through front desk;

e. The public area over 3.5 meters.

The first of these distances is the most defended, except for the dear ones or very close relatives: relatives, the loved ones or friends. It also includes two areas of manifestation: a close (contact) one and a more distant one, which can be reached by the stretched hand. The special studies carried out have shown that taking into consideration, of course, the existing cultural differences, touching the discussion, negotiation partner and especially touching the forearm has a beneficial action on the subconscious, leading to the normalization of the communicative flow, or even speeding up the action of one of the partners in the direction desired by the other.

Speaking of the other areas, they refer either to the distance determined by the arm stretched out with a tight fist and which is accessible to those relatively closer people, to the long time acquaintances from business meetings (the personal area); either at the distance between us and the occasional interlocutors (the social area), or in the case of communication by persons in dominant positions to a group of listeners (the public area).

At this point, we can talk about the intervention of the distance, as well as the ways of manifestation and positioning of the interlocutors, defining the relationship that is born between them. Because the one who draws closer, having a relaxed warm face, already inoculates the other openness, receptivity, unlike those who are waiting motionless, or who position themselves (as we will see) in more remote places, which raise, a priori, communication barriers to the development of interpersonal relationships.

And there is also a matter of interest: the extent of the space occupied by the issuer materialized either by its body dimensions (height above the thickness) or by the occupied space (surface). In the latter case, it has been found that people occupying more space have a relatively high negotiating power. Also, from practice, the more we deal with a more prominent person, the more the person will seek to choose a more impressive office and which imposes a greater distance from the interlocutor.

Not to mention that even the mere choosing a place in a room, by the marking of the personal space by spreading the papers, stretching the legs, everything becomes communication. However, in this context, one should not forget that the "invasion" of this space often produces a feeling of discomfort and impedes upon the individual yield in the established actions. And, the excessive approach can communicate (evoke) strictly personal (acceptance) or even threatening relationships, while the exaggerated distance signals to us the arrogance, the increased self importance, a higher social status of that person. In fact, in all these situations, we are talking about the dimension of property that defines space as a natural extension of the body.

In other words, depending on the distances or proxemics, we can see that the free will and the personality make their mark in choosing the outfit, the accessories, the things and the environment of the apartment we live in, the office and everything that belongs to us.

The knowledge of the use of this nonverbal communication tool will help individuals gain the ability to use it effectively for discovering a territorial breach when it occurs, as well as for making the messages clearly spread across spatial relationships and on which all those involved in that action depend on. 


\section{The inter-relations between leadership and proxemics}

In this sub-chapter, we are not dealing with the implications of nonverbal communication on leadership, but only regarding to Proxemics and space feedback to the persons, leaders in our case.

It's about of a specific concept, a syntagma, "the right/proper distance", which means the measure in which a person respects the inter-personal zones (specified above), in order to ensure the plenary demonstration of the personality and skills for each participant, including the activity of leadership.

Two examples that strenghten the link and the quality of communication between leaders and subordinates, employess, or the listeners (people wanting knowledge), or followers, are the following:

a. The year 2001, somewhere in Afghanistan, at the border, a discussion between a commander (leader) and a subordinate on not strict military problems. When the discussion was outside the tent, in open space, therefore not in military atmosphere, this one was easier from the part of subordinate, succeeded to evoque all problems concerning his life for which he was seeking for solutions and support (Major Crandall, 2007: 226).

b. A personal situation when, during hot afternoon of May (i.e. the second term), I passed together with my students, in a seminar class, in a park and a sweetshop. I've noticed that the distance and reluctance from the class disappeared, the atmosphere was more relaxed and the questions asked were natural, trying to clarify several issues of the course.

As an important partial conclusion, we may affirm that the leader knows to keep a certain limit (our emphasize) between himself and the others and combined with Kinesics, i.e. the language of body, become a powerful aspect in whole communication (Parr Rud, 2012). They are focused on future, on the modalities to fulfill the tasks and to inspire the others the enthusiasm and trustsi increderea to effect activities according to their vision.

\section{Conclusions}

The leader, the charismatic one especially, is not mandatory a dominant personalty. He is acting calmly and wisely in the relationship with the others, and the mastery of nonverbal communication techniques is an important asset and establishes a system of mutual trust, gaining the loyalty of those he works witth, or follow him.

From all the aspects inserted in this paper, we can make it as a quintessence the fact that the keadership is a procedural state through which the leader gather the people (from an entity, organization, society), give it a compelling/persuasive motivation towards a desired goal(s).

A flash on politic field reveals that the majority of states/economies/societies has evolved much in the last years, but it is needed more than ever that the political forces should be awareof the new social realities, of the new challenges what are happening fast, as well as finding leaders to give new impulses and to empower people, in order to achieve the proposed goals.

Due to the analysis even of the politic domain, we realize that the leadership means more than a part of management (and of its functions of driving and motivation), a status regarding the good and efficient using of people (i.e. the Human Resources).

For the purpose of the present paper, we can say that proxemics is influencing the state of leadership and the leader behavior, as part of the larger domain of nonverbal communication. We consider that the distance as a leader to plenary manifest is minimum $120 \mathrm{~cm}$ to increase the efficiency of the actions or manifestations to which he is called to contribute.

But, much more in this respect, the attention must be focused in the arrangement of offices, work spaces, debate spaces, environment of actions, because understanding these distances, the Leader becomes more aware about his position and relations with the others, no matter the domain.

Apart from the relationship with the leadership, proxemics must be seen as a very valuable way of supporting the negotiations, political and related to the marketing, beneficial to both the communicator (the source) and the receiver. By easily managing and manipulating this technique in the postmodern era that we are going through, it is more necessary than ever to communicate and participate in the close interaction between the current global markets and inter-states multiple relationships. 


\section{References}

1. Bennis, B. M., Nanus, B. (2000). Liderii. Strategii pentru preluarea puterii (Leaders. Strategies to take the lead), Business Tech International Press Publishers, Bucharest.

2. Major Crandall, Doug (2007). Leadership Lessons from West Point, John Wiley \& Sons, Inc.

3. Hall, Edward T. (1982). The Hidden Dimension, Anchor Books Editions. Available at www.philoonline.com/TEXTES/HALL Edward Twichell. Accessed August 15, 2017.

4. Hall, Edward T. (1974). Handbook for Proxemic Research, Society for Anthropology of Visual Communication, Washington D.C.

5. Leon, A. L. (2016). Comunicare in Afaceri (Business Communication), Performantica Publishers, Iasi.

6. Mills, Quinn D. (2005). Leadership. How to lead, How to Live, Waltham, MA; MindEdge Press.

7. Myers, G.E., Myers, M.T. (1990). Les bases de la communication interpersonnelle, McGraw-Hill.

8. Nastase, Marian (2004). Cultura organizationala si manageriala (The managerial and organizational culture), ASE Publishers, Bucharest.

9. Neculau, Adrian (2004). Psihologia campului social. Reprezentarile sociale, Polirom Publishers, Iasi.

10. Parr Rud, Olivia (2012). Leadership Techniques: How Is Your Nonverbal Communication? Available at www.oliviagroup.com/leadership. Accessed August 19, 2017.

11. Sheppard, Mike (last update 1996). Proxemics. Available at www.cs.unm.edu/ sheppard/proxemics.htm. Accessed August 13, 2017.

12. Fiedler's Contingency Model, www.mindtools.com/pages accessed August 18, 2017. 